\title{
CAMBRIDGE
}

\section{The Logical Choice}

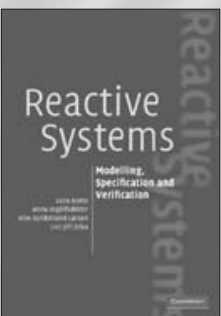

Reactive Systems Modelling, Specification and Verification

Luca Aceto and Anna Ingólfsdóttir Reykjavik University

Kim Guldstrand Larsen and Jiri Srba Aalborg University

- Describes the process algebraic approach to the specification and verification of software and software systems using mathematical logic

GBP 40.00 | HB | 9780521875462 | 2007

\section{Model-Based Software Testing and Analysis with C\#}

Jonathan Jacky University of Washington

Margus Veanes Microsoft Research, Redmond, Washington

Colin Campbell Modeled Computation LLC, Seattle, Washington

Wolfram Schulte Microsoft Research, Redmond, Washington

- Methods developed at Microsoft Research and used by Microsoft product groups

- Source code for tools available on the web

GBP 27.99 | PB | 9780521687614 | 2008
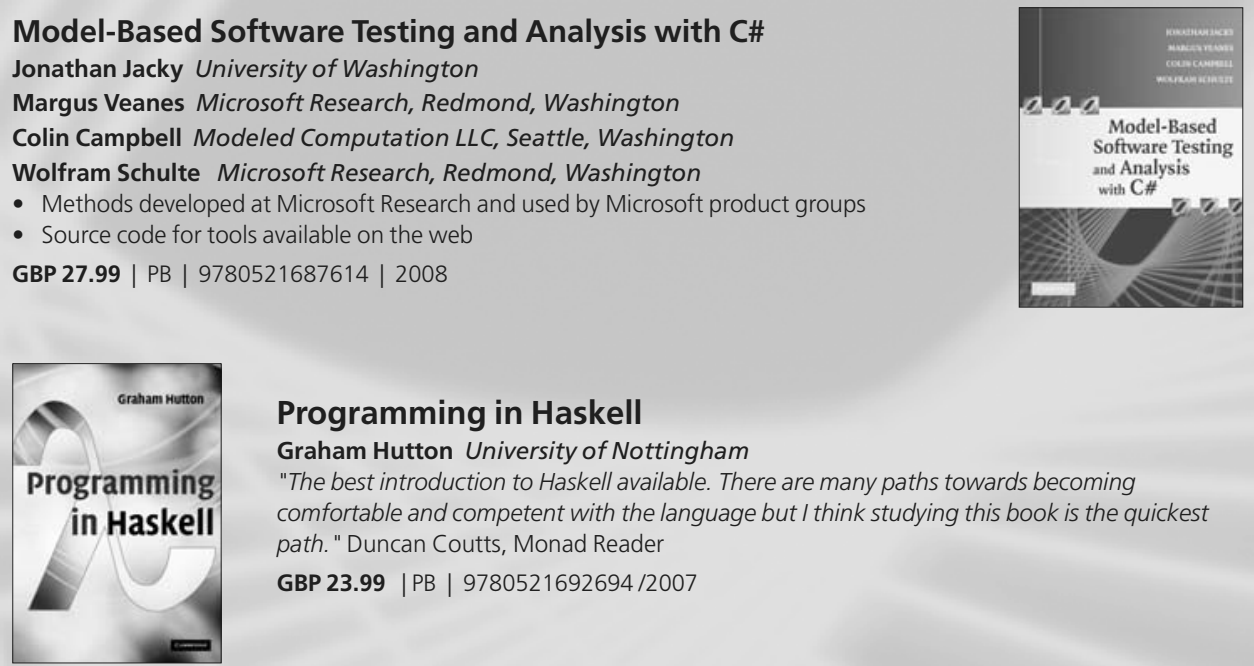

\section{Programming in Haskell}

Graham Hutton University of Nottingham

"The best introduction to Haskell available. There are many paths towards becoming comfortable and competent with the language but I think studying this book is the quickest path. " Duncan Coutts, Monad Reader

GBP 23.99 |PB | $9780521692694 / 2007$

\section{Introduction to Software Testing}

Paul Ammann George Mason University

Jeff Offutt George Mason University

"... has the advantage of presenting concepts and techniques that cover the broad range of languages and platforms used in practice by industry and academia... one of the most thorough and practical testing books ever published" Roger Alexander, Associate Professor, Washington State University

GBP 32.99 | HB | 9780521880381/2008

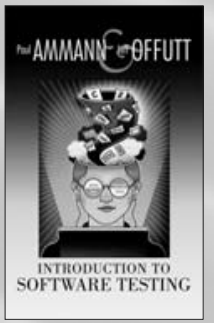

Sign up to our monthly email alerts to keep up-to-date with new titles

www.cambridge.org/alerts

For more info or to order online, please visit www.cambridge.org/computerscience Order by phone: +44 1223326050 
Theory and Practice of Logic Programming (ISSN 1471-0684), is published bi-monthly in January, March, May, July, September and November by Cambridge University Press, The Edinburgh Building, Shaftesbury Road, Cambridge, CB2 8RU, UK/Cambridge University Press, 32 Avenue of the Americas, New York, N.Y. 10013-2473. The subscription price (excluding VAT) of Volume 9, 2009 is $\mathfrak{E}_{270}$ net (USA, Canada and Mexico US\$520), for institutions print and electronic or $\mathfrak{£}_{240}$ net, (USA, Canada and Mexico US\$445) electronic only, single parts cost $\mathfrak{E}_{57}, \$ 100$ plus postage. Discounted individual rates (print only) are $\mathfrak{E} 66, \$ 120$. There is a preferential rate for members of The Association of Logic Programming and The Association of Computing Machinery - please enquire. Six parts form a volume. EU subscribers (outside the UK) who are not registered for VAT should add VAT at their country's rate. VAT registered subscribers should provide their VAT registration number. Orders, which must be accompanied by payment, may be sent to any bookseller, subscription agent or to the publisher: Cambridge University Press, The Edinburgh Building, Shaftesbury Road, Cambridge, Св 2 8RU, or in the USA, Canada and Mexico to Cambridge University Press Journals Fulfillment Department, 10o Brook Hill Drive, West Nyack, New York 10994-2133. Prices include delivery by air where appropriate. Periodicals postage paid at New York, NY and at additional mailing offices, Japanese prices are available from Kinokuniya Company Ltd, P.O. Box 55, Chitose, Tokyo, 156, Japan. Postmaster: send address changes in USA, Canada and Mexico to Journal of Theory and Practice of Logic Programming, Cambridge University Press, 100 Brook Hill Drive, West Nyack, New York 10994-2133. Claims for missing issues should be made immediately on receipt of the subsequent issues.

\section{(c) Cambridge University Press 2009}

\section{INSTRUCTIONS TO AUTHORS}

\section{Aims and scope}

Theory and Practice of Logic Programming is an international journal that publishes refereed papers covering both the theory and the practice of logic programming. Among the topics covered are AI applications that use logic programming, logic programming methodologies, specification, analysis and verification of systems, inductive logic programming, multi-relational data mining, natural language processing, knowledge representation, nonmonotonic reasoning, semantic web reasoning, databases, implementations and architectures and constraint logic programming.

TPLP is the sole official journal of the Association for Logic Programming (http://www.cs.kuleuven.be/ dtai/projects/ALP) and is offered to its members at a preferential rate. It is also endorsed by SPARC, the Scholarly Publishing \& Academic Resources Coalition (URL: www.arl.org/sparc).

\section{Submission of manuscripts}

Electronic submissions: The preferred form of submission is to send two email messages, the first one with the information containing the title, the author(s), and the abstract of the submission, and the second one with a Postscript file. Both emails should be sent to the appropriate Area Editor with a copy to the Editor-in-Chief. If in doubt about the most appropriate area, contact the Editor-in-Chief.

Paper submissions: These are also acceptable, but their handling may be delayed (four copies to the appropriate Area Editor and one copy to the Editor-in-Chief).

The submitted manuscripts should not be published or simultaneously submitted to another journal or to a conference. Full versions of important conference papers are welcome. Upon acceptance of an article by the journal, the author(s) will be asked to transfer copyright of the article to Cambridge University Press.

\section{Book Reviews}

Books for review, or suggestions for reviews, should be sent to the book reviews editor.

\section{Logic Programming Pearls}

Successful cases of elegant and efficient logic programs will appear in a section called Logic Programming Pearls. Please submit to the Logic Programming Pearls editor.

\section{Technical notes}

Technical notes should not exceed 5000 words in length, excluding tables, figures, and the bibliography. They are given quick turnaround and should be submitted, preferably electronically, to the Technical Notes editor. Submissions should include an abstract and a reasonable accurate word count for the paper (excluding tables and figures, and the bibliography).

\section{Electronic manuscripts}

The publisher encourages the submission of final manuscripts written in LaTeX which can be used for direct typesetting. Authors can download style files from the CUP anonymous $\mathrm{ftp}$ site in a packed or unpacked form. The packed form is available from:

ftp://ftp.cambridge.org/pub/texarchive/journals/latex/tlp-cls and the unpacked files are in a directory / unpacked.
Layout

Manuscripts should begin with an abstract of not more than 300 words at the end of which are 4 or 5 keywords. Avoid footnotes whenever possible. Papers should conform to a good standard of English prose; please consult a style guide such as 'The Elements of Style' by Strunk and White, Macmillan, New York. Presenting Programs in one of the following two styles is encouraged: either with identifiers in italic and keywords in bold or entirely in a fixed-width teletype font. Do not begin a sentence with a symbol or identifier name.

\section{Illustrations}

Supply these as eps files as the publisher cannot use original TeX files of illustrations. A hardcopy printout needs to be supplied of each illustration.

\section{References}

The Harvard system of references should be used. See style files.

\section{Proofreading}

Be sure to submit papers in their final form. Typographical and factual errors only may be changed at proof stage. The publisher reserves the right to charge authors for extensive changes to their paper. No page charge is made. The spelling policy of the journal is to follow author's American or British spelling as long as it is consistent within the paper.

\section{Offprints}

A free pdf of the published article will be supplied to each first named author. Papers offprints may be purchased upon request.

Please contact the editors for additional information or clarification of anything above.

\section{COPYING}

The journal is registered with the Copyright Clearance Center, 222 Rosewood Drive, Danvers, MA, 01923, USA. Organisations in the USA who are also registered with the CCC may therefore copy material (beyond the limits permitted by sections 107 and 108 of the US copyright law) subject to payment to CCC of the per-copy fee of $\$ 16.00$. This consent does not extend to multiple copying for promotional or commercial purposes. Code 1471-0684/09 \$16.00. Organisations authorised by the Copyright Licensing Agency may also copy material subject to the usual conditions.

ISI Tear Service, 3501 Market Street, Philadelphia, Pennsylvania 19104, USA, is authorised to supply single copies of separate articles for private use only. For all other use, permission should be sought from Cambridge UK or the American Branch of Cambridge University Press.

\section{Printed by Latimer Trend, Plymouth, UK}




\section{Theory and Practice of Logic Programming}

VOLUME 9 PART 2 MARCH 2009

\section{Contents}

Regular papers

145 A non-termination criterion for binary constraint logic programs

ÉTIENNE PAYET AND FRED MESNARD

165 Logical Algorithms meets CHR: A meta-complexity result for Constraint Handling Rules with rule priorities

LESLIE DE KONINCK

213 On finitely recursive programs

SABRINA BASELICE, PIERO A. BONATTI AND GIOVANNI CRISCUOLO

239 Book review

Endorsed by

Cambridge Journals Online

For further information about this journal please

go to the journal website at:

journals.cambridge.org/tlp 